\section{How to skin an elephant}

\author{
John A. J. Gowlett
}

Making Silent Stones Speak: Human Evolution and the Dawn of Technology. By Kathy D. Schick and Nicholas Toth. Simon and Schuster: 1993. Pp. 351. $\$ 25$.

Louis Leakey, famed for his discoveries at Olduvai Gorge, was also one of the first to bring the stone age to life with dramatic experimental studies. Two American researchers who have greatly developed this tradition are Kathy Schick and Nick Toth. Experimenting and writing two academic generations on from Leakey, they pay generous tribute to their own inspiring teachers at Berkeley in a lively book that aims to evaluate the role of technology in human evolution. This is a timely emphasis: as archaeology strove to give itself a social face in the $1970 \mathrm{~s}$ and 80 s, technology was often overlooked, largely because earlier studies had been excessively typological; but now there is a broader reappraisal.

There is nothing dull in the approach taken by Schick and Toth, who hardly hesitate even to skin an elephant with stone flakes. They do admit that "the sight of a twelve-thousand-pound animal carcase the size of a Winnebago can be quite intimidating", but in a bold experiment small lava flakes proved up to the task. Such work illustrates one of the niches that may have been open to tool-using hominids, who were probably able to cut into carcases whose tough hides held other carnivores at bay. Their studies have led the authors to a respectful interpretation of the early hominids, whose activities show considerable foresight - "not a simple story of the most expedient technology".

Much of the book is a straightforward and up-to-date account of human evolution, but the authors have found several ways of enlivening it. They use italicized chapter introductions to give an 'earlyhominids'-eye' view of the world, pithy quotations to reinforce their points, and numerous action photographs of their own experiments. Each author makes a substantial personal contribution in terms of experimental archaeology. Schick is mainly concerned with how early sites were formed, including the element of human behaviour that can be isolated behind many natural factors. Toth is the replicator of stone artefacts, and thus a discoverer of the routines that govern their manufacture. These complementary approaches give a refreshingly balanced view of human evol- ution, with special insights where the authors' own work is concerned.

One such area is early hominid use of the landscape. Schick has developed the late Glynn Isaac's food-sharing model into a more neutral 'favoured place' hypothesis. This involves hominids returning frequently to places that offer both good food supplies and suitable protection from predators. Another remarkably exciting line of enquiry concerns the abilities of tool-using chimpanzees. To operate their comparative framework, anthropologists have to evaluate any overlaps in ape and human behaviour. Since 1990 the authors have collaborated with Sue Savage Rumbaugh in exploring just how far a chimp can go. A certain Kanzi proves able to appreciate sharp cutting edges and to strike flakes from stones. Chimpanzees are the only primate species apart from humans that regularly make tools. Some recent work has suggested that their ability to do this is on a par with early hominid technology, but this research seems more likely to pinpoint the distinctions that exist. Kanzi, it turns out, is principally employed in communication studies, "so he could only engage in these experiments from time to time". $\mathrm{He}$ is evidently more in de- mand than the poor old robust australopithecine of Toth's lament, consigned to the fringes of human evolution:

I got the Zinjanthropus blues My name's been abused

They call me dumb, they call me thick

My tools don't even do the trick, oh no

I just can't take it no more

I may just do myself in

Down on the FLK floor

Palaeoanthropology is a controversial and often hotly contested field, but there is no edge to this book, other than that of its stone tools. Schick and Toth's pleasure in their work shines through, an enthusiasm that is infectious. They have great confidence that technology is an inescapable part of our heritage, and no scepticism about its role in the present and future. When those silent stones are made to speak, they seem to tell not just of the past but also of those who study them now - like the early hominids, Schick and Toth have taken up stone tools and taken on the world. In this fascinating account they show that stone tools do not just endure, but also have an enduring relevance.

John A. J. Gowlett is in the Department of Archaeology, University of Liverpool, Liverpool L69 3BX, UK.

\title{
The tangled bank revisited
}

\section{G. A. Dover}

Genes in Ecology. Edited by R. J. Berry, T. J. Crawford and G. M. Hewitt. Blackwell Scientific: 1992. Pp. 534. £50, $\$ 109.95$ (hbk); £25, \$52.95 (pbk).

IN ending his most famous advocacy for evolution by natural selection on a lyrical but pertinent note of ". . . the tangled bank. . clothed with varied plants. . birds singing. .. insects flitting... worms crawling. . . dependent on each other in so complex a manner. ..", Darwin firmly tied evolution to its ecological roots. For the ensuing theoretical high priests of evolution spiralling off into other-worldliness, tangled maths replaced tangled banks. Happily, a reversal in attitude is unfolding, following hard on the heels of new molecular and ecological insights that are wresting the study of evolution from its 'Heath Robinson' theoretical contraptions and placing it back firmly in life, as we recognize it, on Earth.

Why did ecologists abandon evolution to the geneticists? Was it because of the perceived difference in timescale between ecological and evolutionary dynamics or because the near-theological battles waged by population geneticists over selection versus neutrality, and other huffs and puffs, left them bemused and generally disenchanted? Ecologists view life as more than balanced polymorphisms, the myth of constant selective values, the selfish-genery of big $A$ versus little $a$, just-so adaptationism and stable equilibria of large single-species populations harmoniously occupying readymade niches. Ecologists were down on their knees in the tangled bank, rooting for cause-and-effect, dissecting the chaotic fluctuations of multi-species interactions, deconstructing the confounding duality of the organism-niche phenomenon, and decomposing the idealized population into its metapopulation substructure; whilst not forgetting for one moment that the individual organism, in all its prime and glory, was the central unit of evolution determining the subsequent fate of each of its thousands of fractious genes. If ever two disciplines were destined to pass each other like ships in the night, they were ecology and evolution, notwithstanding the joint kickstart they got from Darwin.

I exaggerate (of course) in order to polarize the extremes and to give credence to the thrust behind this unusual book and last year's meeting of opposites, in Norwich, England, from which it sprang. The editors rightly judged that 